\title{
Reconstruction of the winter Pacific-North American teleconnection pattern during 1895-1947 and its application in climatological studies
}

\author{
Zhi-Yong Yin \\ Department of Geography, Georgia State University, Atlanta, Georgia 30303, USA
}

\begin{abstract}
The Pacific-North American (PNA) teleconnection pattern is one of the most prominent teleconnection patterns in the Northern Hemisphere winter It manifests as anomalies in the 700 or $500 \mathrm{mb}$ geopotential height field and is closely related to the upper-level flow patterns and surface temperature and precipitation conditions in the United States. Various indices were developed to represent the strength of the PNA teleconnection. However, their application in climatological research is limited by a short record length as continuous upper-level measurements are widely available only since 1947. The purpose of this study is to reconstruct the winter PNA pattern for the period 1895 to 1947. A regression model is developed based on the relationship between the PNA pattern, represented by a PNA index, and surface temperature anomaly field across the continental United States. The model can explain over $89 \%$ of the variance in the PNA index and offers unbiased estimates. Using this model, the winter PNA index is extended back to the 1895-96 winter. Analysis of winter precipitation anomalies in the United States from 1895 to 1988 illustrates the application potential of this extended record. With a longer record length, more extreme cases of the PNA teleconnection can be identified to analyze its relation to surface conditions. The extended PNA index is useful in explaining the cooling trend from the 1940 s to the $1970 \mathrm{~s}$ in the eastern United States. It is also significantly related to an extended Southern Oscillation index from 1895 to 1988 . However, the relationship is not strong enough to suggest a completely synchronized occurrence of the 2 teleconnection patterns.
\end{abstract}

KEY WORDS: Pacific-North American teleconnection pattern · Climate of the United States - El Niño/ Southern Oscillation

\section{INTRODUCTION}

Teleconnections are the association of atmospheric anomalies over great distance, which often manifest as persistent relationships between pressure fields of various geopotential heights at far-apart locations (Glantz 1990). Teleconnections may be related to general circulation patterns as well as to surface climatic conditions. The most well-known teleconnections that may affect weather conditions in the continental United States include the Pacific-North American (PNA) teleconnection pattern, the North Atlantic Oscillation (NAO), and the El Niño/Southern Oscillation (ENSO) (Wallace \& Gutzler 1981, Rogers 1984, Yarnal 1985). The PNA pattern is probably the most important pattern in Northern Hemisphere winters (Simmons et al. 1983). In a comprehensive study on teleconnections, Wallace \& Gutzler (1981) analyzed the winter $500 \mathrm{mb}$ geopotential height field data in the Northern Hemisphere. They identified 5 strong patterns and the PNA teleconnection pattern was one of the most prominent. In a more recent study, Barnston \& Livezey (1987) identified at least 13 teleconnections in the monthly $700 \mathrm{mb}$ geopotential height field using principal component analysis (PCA). Again, the PNA was one of the strongest among these patterns during the winter months.

The PNA pattern is related to the long waves in the mid-troposphere in the Northern Hemisphere extratropical regions. Normally there is an upper-level ridge along the Rockies and troughs over the Aleutian area in the northeast Pacific and over the eastern United States. The locations of the mean standing waves 
reflect the effects of topographic forcing of major mountain systems, such as the Rockies and Tibetan Plateau, and land-sea thermal contrasts along the Pacific and Atlantic coasts. Detailed descriptions of the characteristics of the PNA pattern and its relation to the upper-level flow patterns were given by Yarnal \& Leathers (1988) and Leathers et al. (1991). The PNA teleconnection pattern has 2 phases. The first phase (PNA) is the classic PNA pattern, characterized by deeper-than-normal troughs over the Aleutian area and the eastern United States and a higher-thannormal ridge over the Rockies. A more meridional upper-level flow pattern across North America is associated with this phase. The opposite phase (RPNA) is characterized by filled troughs over the Aleutian area and eastern United States, and a lowered ridge over the Rockies. A more zonal upper-level flow pattern is associated with this phase (Fig. 1). Under extreme cases of the RPNA phase, a trough may be found over the Rockies and ridges over the Aleutian area and eastern United States.

Previous studies have shown that the PNA pattern is significantly related to surface weather conditions in various parts of the continental United States. The PNA phase tends to bring above-normal temperatures to the western United States. Under its influence, the southwestern United States is affected by the upperlevel ridge and may experience blocking and drought conditions (Yarnal \& Diaz 1986, Leathers et al. 1991). In the meantime, the eastern United States, especially the southeast, may experience intrusions of polar or arctic air masses with enhanced cyclonic activity (Yarnal \& Leathers 1988, Leathers et al. 1991). During the RPNA

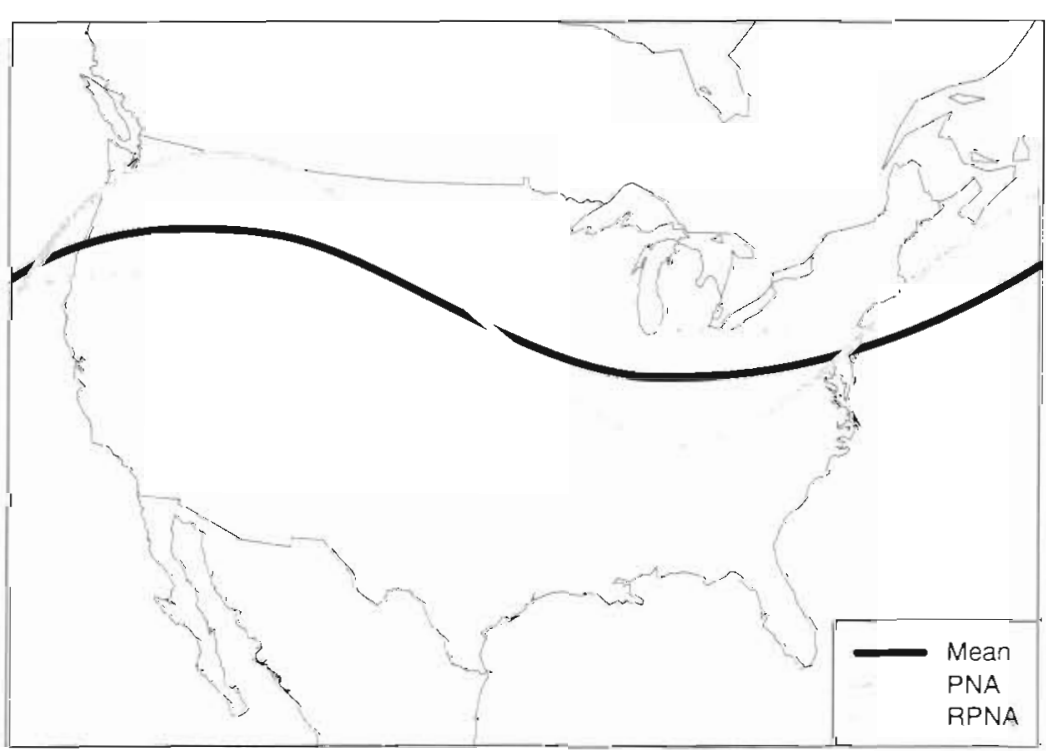

Fig. 1. Schematic upper-level flow patterns across the North American continent during the PNA and RPNA phases. (Adapted from Leathers et al. 1991) phase, the western United States may experience relatively cold and wet conditions, while the eastern United States is under dry and warm conditions (Yarnal \& Diaz 1986). On a more local scale, Yarnal \& Leathers (1988) examined the relationship between the PNA teleconnection pattern, represented by a PNA index, and surface temperature and precipitation in Pennsylvania. State-wide temperature and divisional precipitation in 4 out of 10 climate divisions in Pennsylvania were found to be significantly related to the PNA index. Robinson \& Walsh (1991) found that the PNA index was statistically related to both the frequency and magnitude of precipitation events in North Carolina and various parts of the southeastern United States. The PNA index is also significantly related to the Palmer's Drought Severity Index across the southeastern United States (Yin 1994). As the phase change of the PNA teleconnection pattern varies from weeks to months (Blackmon et al. 1984a, b, Esbensen 1984), this teleconnection may be useful in mid- to longrange weather forecasting.

Various indices have been designed to evaluate the strength of the PNA teleconnection pattern using $500 \mathrm{mb}$ or $700 \mathrm{mb}$ geopotential height anomaly data (Horel \& Wallace 1981, Wallace \& Gutzler 1981, Yarnal \& Diaz 1986). Despite the potential usefulness of the PNA indices, applications in climatological research are often limited by the short record length. The data needed to calculate these PNA indices are only available since 1947 when the upper-level observations began to be widely available. Such a record length may not be enough in studies of interannual variability and long-term trends. In addition, a short record tends to contain few extreme cases. Therefore, it is difficult to examine the atmospheric conditions during extreme phases of the PNA teleconnection pattern.

The purpose of this study is to reconstruct the winter PNA teleconnection pattern based on the relationship between the $700 \mathrm{mb}$ height field and surface temperature anomalies across the continental United States. Previous studies have shown that winter surface temperatures in the continental United States are closely related to the $700 \mathrm{mb}$ height field. By selecting 4 warm winters and 4 cold winters during the period 1948 to 1980 , Erickson (1984) found that warm winters in the United States tended to coincide with positive anomalies of the $700 \mathrm{mb}$ height field, while in cold winters the inverse pattern occurred. Klein \& Kline (1984) analyzed correlation fields between surface 
monthly temperature anomalies at 109 weather stations and the $700 \mathrm{mb}$ height anomaly field during the winter months from 1948 to 1981 . The correlation coefficients were as high as 0.92 . Similar results were also derived by Skeeter (1990) using $500 \mathrm{mb}$ height field data. As temperature data are widely available and have much longer records than the upper-level pressure measurements, it is possible to obtain a longer record of the PNA teleconnection pattern if the relationship between the temperature anomaly field and PNA teleconnection pattern can be specified. In the present study, possible applications of such an extended PNA record will be explored through investigations of spatial and temporal variations in winter temperature and precipitation anomalies in the continental United States. An attempt is also made to examine the relationship between the PNA and ENSO teleconnection patterns.

\section{DATA AND METHODS}

Monthly temperature and precipitation data for climate divisions were used in this study. Climate divisions are areas with relatively homogeneous climatic conditions. They are delineated along either physiographical or political boundaries. There are 344 climate divisions in the continental United States. The divisional temperature and precipitation data are derived by averaging measurements at the weather stations within each division. The data are available for the period 1895 to 1988 . To reduce the errors associated with the uneven area represented by each division, the divisions nearest to the $5^{\circ} \times 5^{\circ}$ grid points were selected to form a data set containing 48 evenly distributed climate divisions (Fig. 2). Then the monthly divisional temperature and precipitation data were treated as point measurements taken at the centroids of the climate divisions. Similar schemes have been used by Karl \& Koscielny (1982), Englehart \& Douglas (1985), and Klein \& Bloom (1987). For each division, seasonal mean temperature and total precipitation were calculated for the 3 winter months, December, January, and February, from the 1895-96 winter to the 1987-88 winter. The seasonal values were then standardized by the long-term mean and standard deviation to obtain the anomalies.

The PNA index (PNAI) as described in Yarnal \& Diaz (1986) was chosen to represent the PNA teleconnection pattern. This index is based on the normalized $700 \mathrm{mb}$ geopotential height anomalies $(z)$ at locations near the centers of the PNA anomaly pattern: the Aleutian area $\left(47.9^{\circ} \mathrm{N}, 170.0^{\circ} \mathrm{W}\right)$, northern Rockies in southwestern Canada $\left(49.0^{\circ} \mathrm{N}, 111.0^{\circ} \mathrm{W}\right)$, and southeastern United States $\left(29.7^{\circ} \mathrm{N}, 86.3^{\circ} \mathrm{W}\right)$ :

$$
\begin{aligned}
\text { PNAI }=\frac{1}{3}[ & -z\left(47.9^{\circ} \mathrm{N}, 170.0^{\circ} \mathrm{W}\right)+z\left(47.9^{\circ} \mathrm{N}, 111.0^{\circ} \mathrm{W}\right) \\
& \left.-z\left(29.7^{\circ} \mathrm{N}, 86.3^{\circ} \mathrm{W}\right)\right] .
\end{aligned}
$$

During the PNA phase, there is a positive $700 \mathrm{mb}$ height anomaly over the Rockies and negative anomalies over the Aleutian area and southeastern United States. Therefore, the index will render a positive value. During the RPNA phase, there is a negative $700 \mathrm{mb}$ height anomaly over the Rockies and positive anomalies over the Aleutian area and southeastern United States. Thus the index will render a negative value. If the $700 \mathrm{mb}$ height field is close to the longterm average condition, the index should give a value close to zero. Seasonal PNAI values were calculated as the average of the 3 winter months from the 1947-48 winter to the $1987-88$ winter.

Fig. 2. Locations of the 48 climate divisions in the continental U.S. used in this study

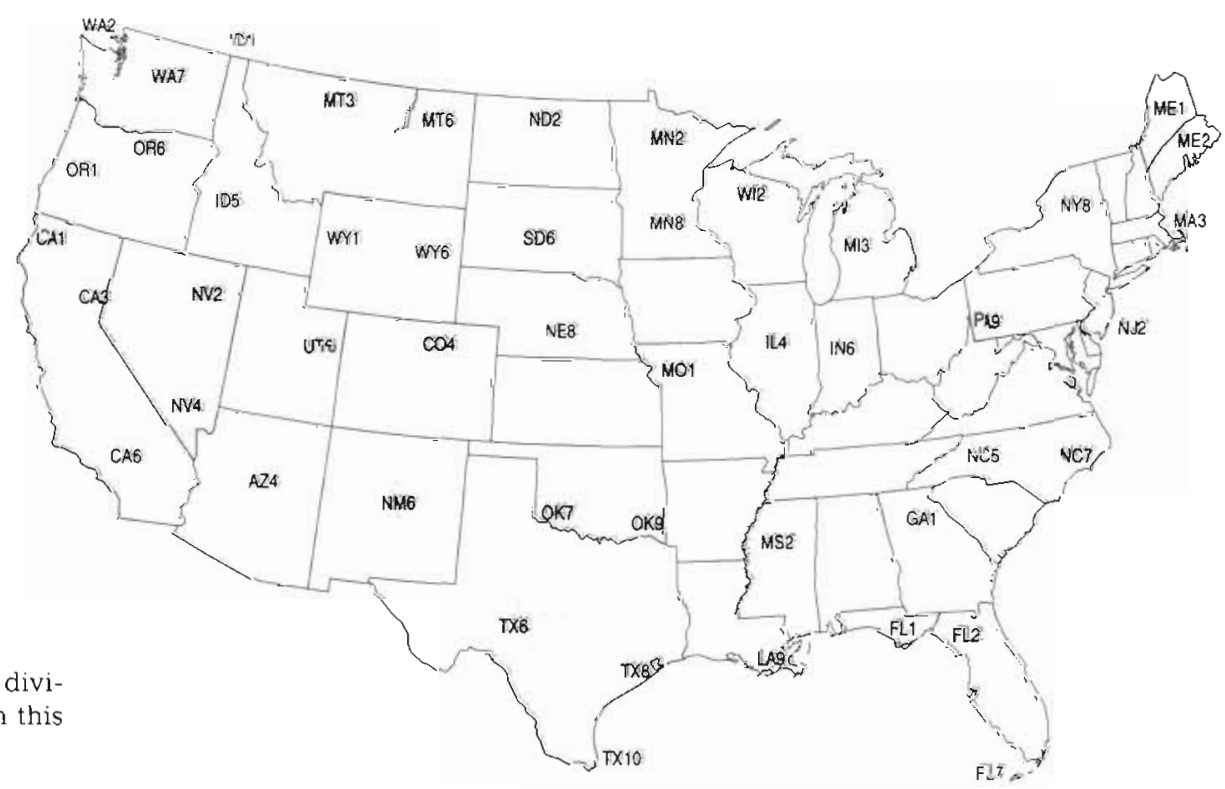


Regression analysis seems to be a proper method to quantify the relationship between the PNAI and temperature anomalies of the selected climate divisions. However, the temperature anomaly field data contain strong spatial autocorrelation and therefore redundant information. By using divisional temperature anomalies directly as the independent variables in multiple regression analysis, the assumption of independence among independent variables would be violated. To avoid this problem, principal component analysis (PCA) was first performed on the temperature anomaly data to reduce the number of variables of the data set and eliminate autocorrelation (Johnston 1978). PCA produces a new set of variables, namely the principal components (PCs). The first PC represents most of the variance in the original data; the second $\mathrm{PC}$ represents most of the remaining variance and is orthogonal to the first PC. In other words, the correlation between the first and second PCs is zero. The third PC represents most of the remaining variance after the first and second PCs are extracted, and is orthogonal to the first $2 \mathrm{PCs}$. If the number of PCs is the same as the number of variables in the original data set, then the new data set represents $100 \%$ of the variance in the original data. Most likely, however, due to the autocorrelation among the original variables, the resulting data set has fewer variables than the original data set and retains most of the variance. In analyzing spatial data, such as the divisional temperature anomalies, each of these PCs may represent a relatively homogeneous area of similar regimes. Scores of these PCs were calculated as linear functions of the original variables and then used as the independent variables in multiple regression against the PNAI.

A potential problem concerning PCA of spatial data is the domain dependence (Richman 1986). Spatial patterns represented by the PC loadings may simply be the result of domain shape. After reviewing many previous studies, Richman (1986) suggested rotation of the PCs before their physical meanings are interpreted. In this study, the method of VARIMAX was used; this is the most commonly used orthogonal rotation method, in which the variation in PC loadings is maximized by maximizing the number of near-zero loadings (Richman 1986). As a result, the differences between these PCs were increased so that the rotated $P C s$ represent more distinct geographical regions than the unrotated PCs. Temporal variations in precipitation anomalies in various regions across the continental United States, represented by the rotated PC scores, were examined in light of the temporal variation in the PNA pattern. In investigating the relationship between the PNA and ENSO teleconnection patterns, correlation and ANOVA were used.

\section{RESULTS AND DISCUSSION}

\section{Reconstruction of the winter PNA pattern record}

In PCA, the scree method was used to help determine the number of PCs to be retained (White et al. 1991). This scheme resulted in 6 PCs explaining nearly $90 \%$ of the variance in the temperature anomaly field (Table 1). The maps in Fig. 3 display the loadings or the correlation coefficients between the PCs and the original variables, divisional temperature anomalies. Therefore, region(s) in which temperature anomalies are highly correlated with a given PC can be defined. For example, the first $\mathrm{PC}$ represents most of the eastern United States with the highest loadings in the Carolinas. This PC is also negatively related to the temperature anomaly along the western coast. The second PC represents the Great Plains, and the third PC represents both the southwest and extreme northeast. As regionalization is not the purpose at this step, the unrotated PC scores were used directly in regression analysis. The significance level for a PC to enter or to be removed from the regression model was set at 0.10 to avoid omitting any important variables. The stepwise procedure identified PC1, PC2, PC3, PC4, and PC6 for inclusion in the multiple regression model (Table 2). The first PC apparently is the most important independent variable. It alone explains $63 \%$ of the variance in the winter PNAI.

The regression model explained over $89 \%$ of the variance in the PNAI, indicating a very good fit. This is also illustrated by plotting values of the estimated and measured winter PNAI over time during the period 1947 to 1988 (Fig. 4). When the residuals are plotted against the 5 independent variables or PCs (Fig. 5a to e) and over time (Fig. 5f), there are no apparent patterns, suggesting unbiased estimates. In a 1 -sample Kolmogorov-Smirnov test on the normality of the residuals, the null hypothesis of a normal distribution could not be rejected at the 0.05 significance level. A comparison using the 2-sample Kolmogorov-

Table 1. Eigenvalues and the proportions of explained variance of the temperature principal components

\begin{tabular}{|ccc|}
$\begin{array}{c}\text { Temperature } \\
\text { principal component }\end{array}$ & Eigenvalue & $\begin{array}{c}\text { Proportion of } \\
\text { explained variation }\end{array}$ \\
\hline PC1 & 17.117 & 0.3566 \\
PC2 & 14.412 & 0.3002 \\
PC3 & 6.799 & 0.1416 \\
PC4 & 1.934 & 0.0403 \\
PC5 & 1.553 & 0.0324 \\
PC6 & 1.282 & 0.0267 \\
Total & & 0.8979 \\
\hline
\end{tabular}




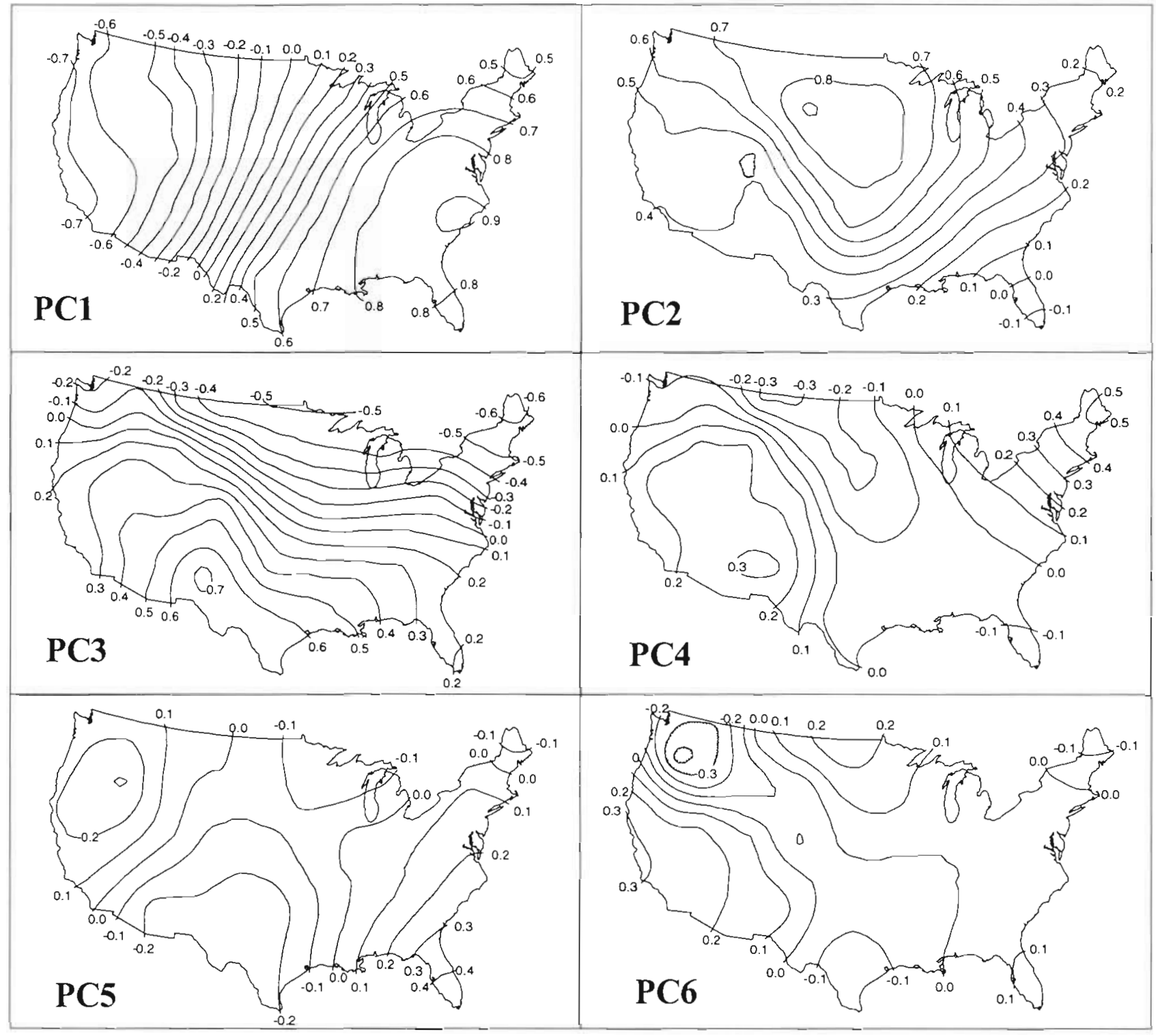

Fig. 3. Loading maps of the 6 temperature PCs

Smirnov test between the estimated and measured PNAI values from 1947 to 1988 indicated that the 2 series probably have the same type of distributions.
Therefore, the estimated values should have statistical characteristics similar to those of the measured values.

Table 2. Stepwise multiple regression on the winter PNA index and the temperature PCs from 1947 to 1988

\begin{tabular}{|c|c|c|c|c|c|c|c|}
\hline \multicolumn{4}{|c|}{ Stepwise regression: } & \multicolumn{4}{|c|}{ Regression model for the PNA index: } \\
\hline Step & PCs entering the model & Partial $r^{2}$ & Model $\Gamma^{2}$ & Variable & Coefficient & Significance & $r^{2}$ \\
\hline 1 & PC1 & 0.6322 & 0.6322 & Intercept & 0.0323 & 0.4028 & 0.8925 \\
\hline 2 & PC3 & 0.1229 & 0.7551 & $\mathrm{PC} 1$ & -0.4313 & 0.0001 & \\
\hline 3 & $\mathrm{PC} 2$ & 0.1045 & 0.8595 & $\mathrm{PC} 2$ & 0.2143 & 0.0001 & \\
\hline 4 & PC6 & 0.0240 & 0.8835 & $\mathrm{PC} 3$ & -0.2216 & 0.0001 & \\
\hline \multirow[t]{2}{*}{5} & $\mathrm{PC} 4$ & 0.0090 & 0.8925 & PC4 & -0.0605 & 0.0952 & \\
\hline & & & & PC6 & 0.0945 & 0.0111 & \\
\hline
\end{tabular}






Fig. 4. Measured and estimated winter PNA index values from the $1947-48$ winter to the $1987-88$ winter
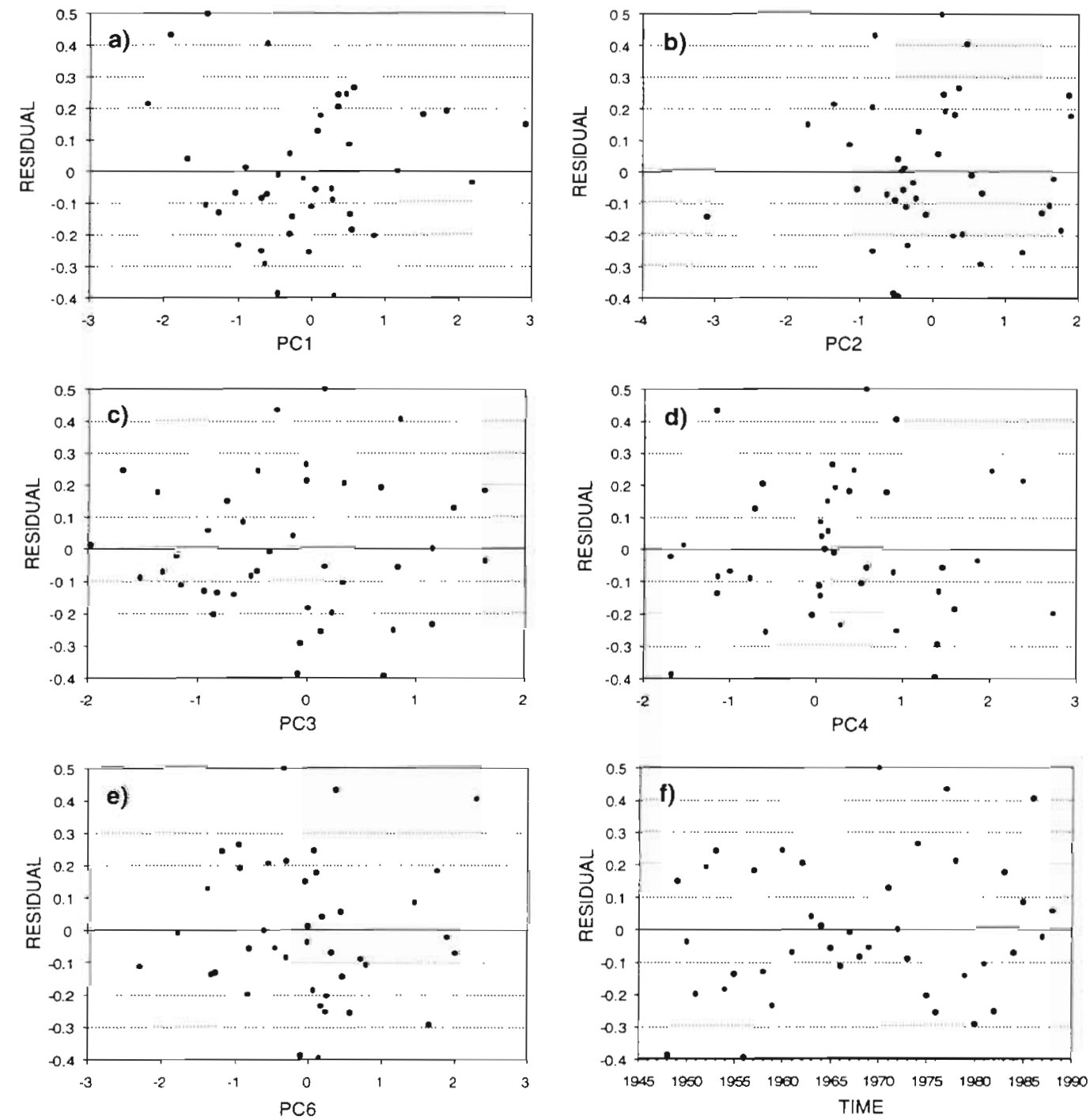

Fig. 5. Residuals of the estimated PNA index plotted against the 5 temperature PCs used in the regression model, and over time 
Fig. 6. Extended winter PNA index from the 1895-96 winter to the $1987-88$ winter

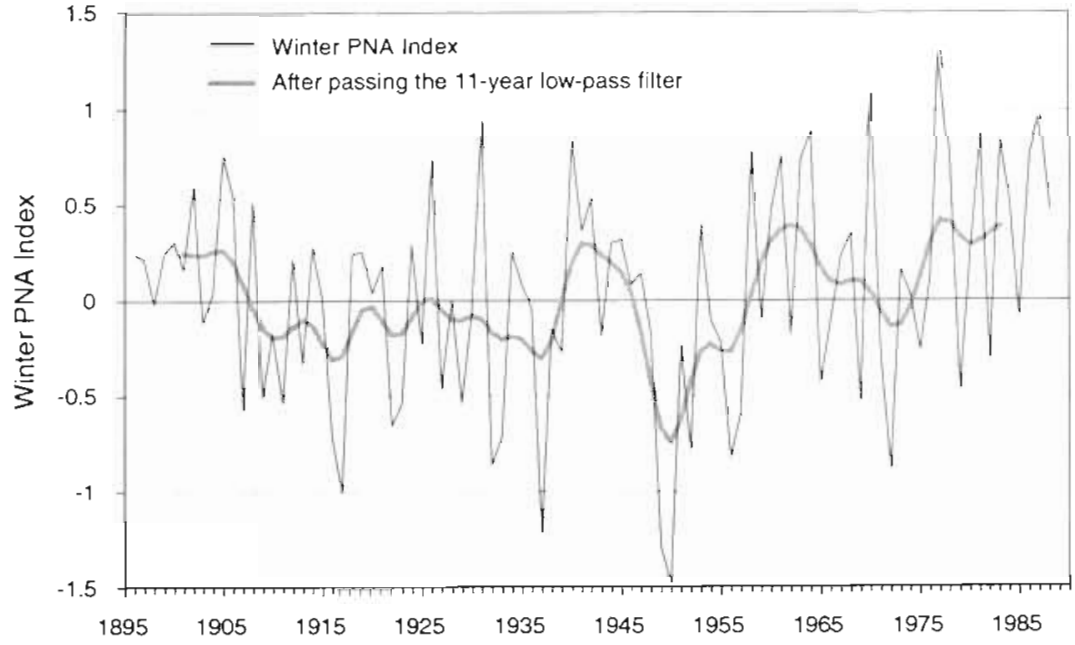

Using the above regression model, the winter PNAI was extended back to the 1895-96 winter. Fig. 6 shows the extended PNA index from the winter of 1895-96 to the winter of 1987-88. To eliminate short-term interannual variations in the record, the time-series was passed through an 11-year low-pass filter. The weights of this filter (Table 3) are based on the Gaussian function as described by Mitchell et al. (1966). The values before the $1947-48$ winter are estimated by the regression model and those afterwards are the original index values. According to the result from a KolmogorovSmirnov test, the extended PNAI seems to be normally distributed. Table 4 contains selected descriptive statistics and typical values of the extended PNAI for given return intervals based on a normal distribution.

\section{PNA and spatial pattern of precipitation anomalies}

Fig. 7 contains results of correlation between the winter PNAI and winter precipitation anomalies for the periods 1947 to 1988 and 1895 to 1988 . There are only minor differences in maps of the Pearson's product correlation coefficients during the 2 different time periods (Fig. 7a, c). These patterns generally conform

Table 3. Weights of an 11-year low-pass filter based on the Gaussian function

\begin{tabular}{|ll|}
\hline \multicolumn{1}{|c|}{ Time } & Weight \\
\hline Year $t$ & 0.2380 \\
Years $t-1$ and $t+1$ & 0.1988 \\
Years $t-2$ and $t+2$ & 0.1159 \\
Years $t-3$ and $t+3$ & 0.0471 \\
Years $t-4$ and $t+4$ & 0.0134 \\
Years $t-5$ and $t+5$ & 0.0026 \\
\hline
\end{tabular}

with results from previous studies (Leathers et al. 1991). However, it seems that the areas with statistically significant correlations are enlarged in the map of the longer record (Fig. 7d). The longer record also suggests that winter precipitation anomalies in southern California and Arizona are significantly related to the PNA teleconnection pattern (Fig. 7d), which is not shown on the map for the shorter record (Fig. 7b).

According to Leathers et al. (1991), during winters with the PNA pattern, the deepened trough over the eastern United States causes the jet stream and associated storm tracks to shift southward. Therefore, the Ohio Valley and Upper Mississippi Valley tend to have below-normal precipitation. The polar and arctic continental air masses dominate this region and further decrease precipitation. In the meantime, the southeast experiences above-normal precipitation due to increased cyclonic activity. In the western United States, the enhanced ridge over the Rockies may cause

Table 4. Selected descriptive statistics and representative values of the extended winter PNA index for various return intervals

\begin{tabular}{lcc} 
Time period & $1895-96$ to $1987-88$ winter \\
Number of observations & 93 \\
Mean & 0.03 \\
Standard deviation & 0.56 \\
Maximum & 1.29 \\
Minimum & -1.48 \\
& \multicolumn{3}{c}{ PNAI value } \\
Return & PNA phase RPNA phase \\
interval & 0.75 & -0.69 \\
& \multicolumn{3}{c}{ R } \\
$10 \mathrm{yr}$ & 0.95 & -0.89 \\
$20 \mathrm{yr}$ & 1.18 & -1.12 \\
$50 \mathrm{yr}$ & 1.33 & -1.27 \\
$100 \mathrm{yr}$ & &
\end{tabular}



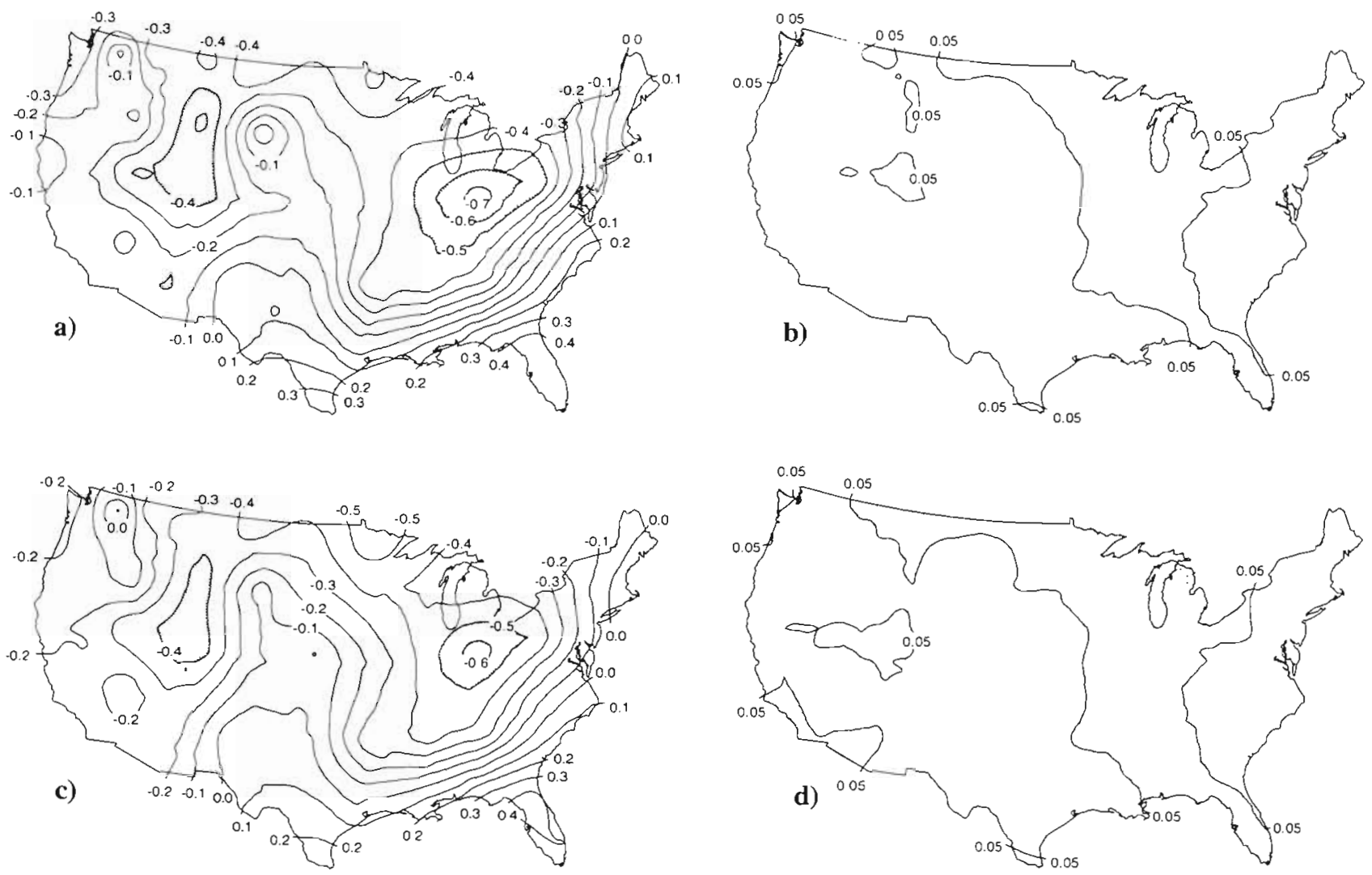

Fig. 7. Correlation between winter precipitation anomaly and the PNA index. (a) Correlation coefficients based on data for 1947 to $1988_{;}$(b) areas (shaded) with significant correlation in (a) $)_{i}$ (c) correlation coefficients based on data for 1895 to $1988_{i}$ (d) areas (shaded) with significant correlation in (c)

strong subsidence and push the westerlies northward. Both processes may cause decreases in precipitation in the region. During winters with the RPNA pattern, the jet stream and the associated storm track shift northward in the eastern United States. The Ohio Valley and Upper Mississippi Valley experience increased cyclonic activity. Maritime air masses from the Gulf of Mexico may intrude further inland and bring above-normal precipitation to the region. The southeast may have a relatively dry period. In the west, the zonal flow and sometimes northwesterly flow will bring Pacific storms to the region. Both the Rockies and the coastal area will have above-normal precipitation.

Perhaps the greatest value of a longer record is the capability to extract a larger number of extreme cases. Based on the winter PNAI for the period 1947 to 1988 , there were approximately 11 and 7 extreme PNA and RPNA winters respectively (Fig. 4). Composite maps of surface climatic conditions based on so few events may not be representative, especially in the case of the extreme RPNA winters (Fig. 8a, b). In the present study, a strong PNA winter is defined as one in which the extended PNAI is above 1.0 standard deviation $(0.5600)$ from the long-term mean $(0.03232)$, and a strong RPNA winter as one in which the index is below 1.0 standard deviation from the mean. There were 16 strong PNA and 17 strong RPNA winters during the 93 winters (Table 5). Composite maps were then produced to show the spatial patterns of precipitation anomalies during the 2 PNA teleconnection phases (Fig. 8c, d)

The composite maps provide quantitative information on the spatial patterns of precipitation anomalies in relation to the PNA teleconnection pattern, and they in general conform well with the maps of correlation coefficients (Fig. 7). During the PNA phase, most of the continental United States is characterized by negative precipitation anomalies. Major centers of negative anomaly are located in a region including the Great Lakes area and the midwest, and another along the central Rockies. Positive anomalies only occur along the south Atlantic and Gulf coasts. Comparison between the 2 sets of maps in Fig. 8 shows little differences for this phase. During the RPNA phases, most of the continental United States is characterized by positive precipitation anomalies. Centers with high positive anomalies are found in the central Rockies and southern California, northern Great Plains, and the midwest. Negative 

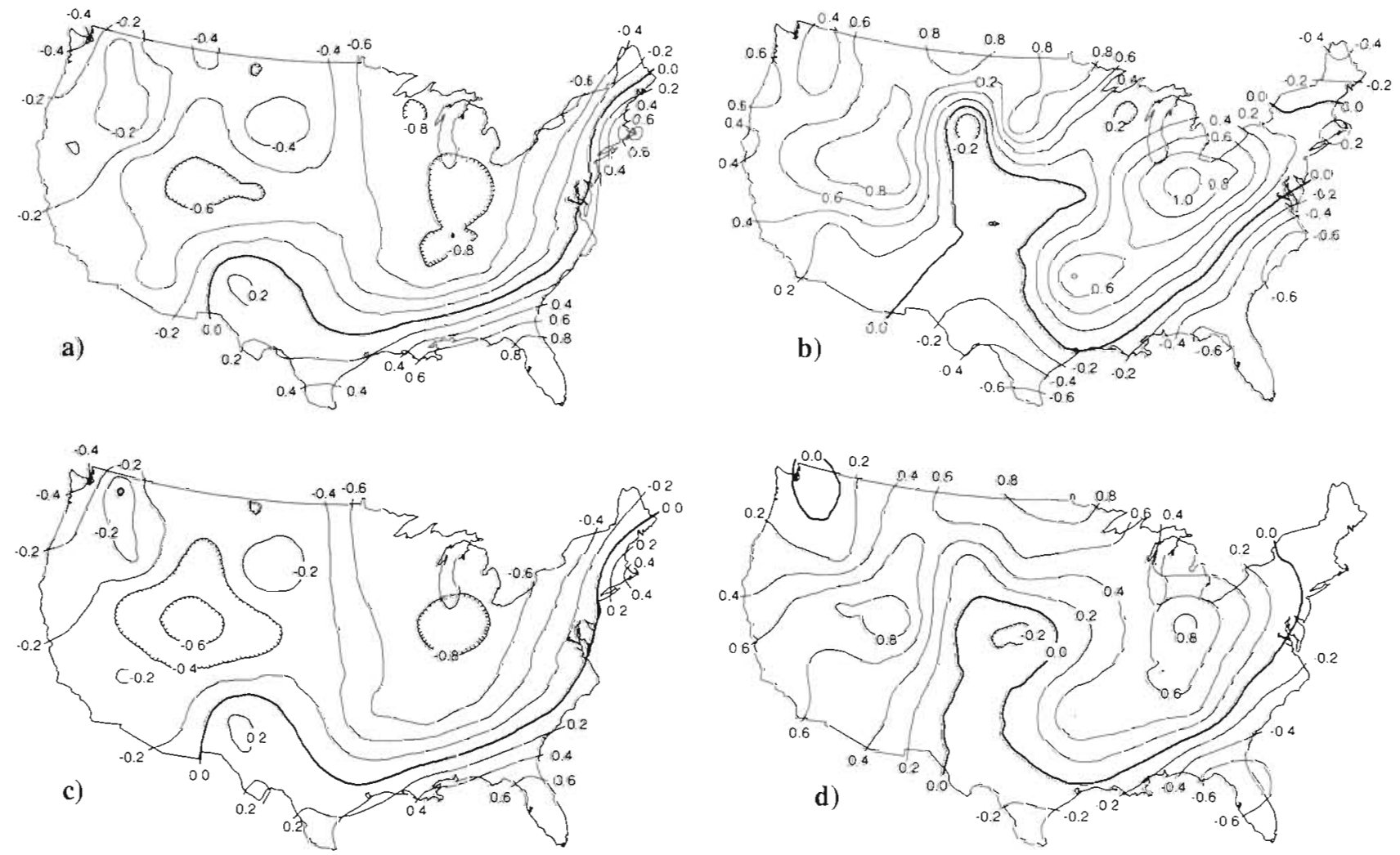

Fig. 8. Composite maps of precipitation anomalies during the PNA and RPNA phases: (a) PNA from 1947 to 1988; (b) RPNA from 1947 to 1988 ; (c) PNA from 1895 to 1988 ; (d) RPNA from 1895 to 1988

anomalies occur in the southern Great Plains and along the southeastern coasts. Apparently the greatest difference between the maps for 1947-1988 and 1895-1988 is in the southwestern United States. The longer record

Table 5. Strong PNA and RPNA winters from 1895-96 to $1987-88$

\begin{tabular}{|cccc|}
\hline \multirow{2}{*}{ PNA } & \multicolumn{2}{c|}{ RPNA } \\
Year & Index & Year & Index \\
\hline 1902 & 0.59 & 1907 & -0.57 \\
1905 & 0.75 & 1911 & -0.54 \\
1926 & 0.73 & 1916 & -0.72 \\
1931 & 0.93 & 1917 & -1.00 \\
1940 & 0.83 & 1922 & -0.66 \\
1958 & 0.77 & 1923 & -0.54 \\
1961 & 0.75 & 1929 & -0.54 \\
1963 & 0.74 & 1932 & -0.86 \\
1964 & 0.88 & 1933 & -0.72 \\
1970 & 1.07 & 1937 & -1.21 \\
1977 & 1.29 & 1949 & -1.29 \\
1978 & 0.74 & 1950 & -1.48 \\
1981 & 0.86 & 1952 & -0.78 \\
1983 & 0.83 & 1956 & -0.82 \\
1986 & 0.77 & 1957 & -0.59 \\
1987 & 0.96 & 1969 & -0.53 \\
& & 1972 & -0.88 \\
& & & \\
\hline
\end{tabular}

displays more significant positive anomalies in this region for the RPNA phase.

\section{Temporal variations in PNA pattern and climatic conditions}

The measured PNAI displays an obvious increasing trend from 1947 to 1988 (Fig. 4). Yarnal \& Leathers (1988) also noted this trend. As the data record is short, it is difficult to evaluate the importance of this trend. Is it a long-term trend that began long before 1947, or a cyclic variation pattern on the secular time scale? Lambert (1990) noticed discontinuities in the $500 \mathrm{mb}$ height data around the mid-1950s, and suggested that the discontinuities may have resulted from changes in the observation method that occurred in 1957. Leathers \& Palecki (1992) examined upper-level measurements and surface temperatures at several stations in the southeastern United States. Their results seem to indicate a real change in the flow pattern from a zonal to meridional nature around 1955 . When the extended record was examined, the change from the zonal to meridional flow pattern apparently started in the early 1950 s and continued into the 1980s (Fig. 6). Prior to this period, there seemed to be only random short-term 
variations. The loading map in Fig. 3 suggests that PC1 of temperature anomalies is positively correlated with temperature anomalies in most of the eastern United States and negatively correlated with temperature anomalies in the western United States. When the score of this PC is high, the eastern United States tends to have warmer-than-normal winters, while the west may experience colder-than-normal winters. When the score is low, the opposite pattern may occur. Such an oscillation pattern is typical during the RPNA and PNA phases respectively. This is why $\mathrm{PC} 1$ alone explained $63 \%$ of the variance in the PNA index. More interestingly, from the 1940 s to the 1970 s there is a significant decreasing trend in the PC score, indicating cooling in the eastern United States and warming in the west (Fig. 9). This trend coincides very well with the increasing trend in the PNA index, indicating enhanced strength of the PNA phase during this period.

Many scholars have noted the cooling trends between the 1950s and early 1980s in the eastern United States. For example, Agee (1980) pointed out that most of the eastern United States experienced abnormally cold winters during this period. van Loon \& Williams (1977) found that there were cooling trends in the eastern United States accompanied by warming trends in the west from 1949 to 1972 . They also compiled the tracks of January cyclones crossing the 70th meridian between the 30th and 50th parallels during the same period. The total cyclone frequency remained essentially constant while the highest frequency shifted to the south in the area, probably as the result of a more meridional upper-level flow pattern and the southward shift of the polar jet stream. In addition, Zishka \& Smith (1980) noted that the number of January cyclones decreased in the western United States while the storms in the east became stronger from 1950 to 1977. Apparently, the increased strength of the PNA pattern during this period offers at least a
Table 6. Eigenvalues and proportions of explained variance of the rotated precipitation principal components

\begin{tabular}{|ccc|}
\hline $\begin{array}{c}\text { Precipitation } \\
\text { principal component }\end{array}$ & $\begin{array}{c}\text { Rotated } \\
\text { eigenvalue }\end{array}$ & $\begin{array}{c}\text { Proportion of } \\
\text { explained variation }\end{array}$ \\
\hline PC1 & 5.834 & 0.1215 \\
PC2 & 4.593 & 0.0957 \\
PC3 & 3.979 & 0.0829 \\
PC4 & 3.976 & 0.0828 \\
PC5 & 3.946 & 0.0822 \\
PC6 & 3.570 & 0.0744 \\
PC7 & 3.452 & 0.0719 \\
PC8 & 3.193 & 0.0665 \\
PC9 & 2.005 & 0.0418 \\
Total & & 0.7197 \\
\hline
\end{tabular}

partial explanation for the temperature variation in the United States. Inversely, the temperature trends seem to prove the validity of the trend in the PNAI. It should be noted that the temperature PCs and the PNAI are not exactly independent, as part of the latter was estimated using the temperature data. However, the estimated portion, 1895 to 1947 , really just provides the background to reveal the trend in the later half of the study period as no long-term trend is visible during the earlier period.

To investigate temporal variability in precipitation anomalies in various regions in relation to the INA teleconnection pattern, PCA was conducted on the divisional precipitation anomaly data. Nine precipitation PCs were retained with the assistance of the scree method. Due to great spatial variation in the precipitation anomaly data, the $9 \mathrm{PCs}$ only explained about $72 \%$ of the variance in the original data, much less than the amount explained by the 6 temperature PCs. Then the precipitation PCs were rotated to alleviate the problem of domain dependence using the VARIMAX method. Listed in Table 6 are the rotated eigenvalues and proportions of the explained variance in the

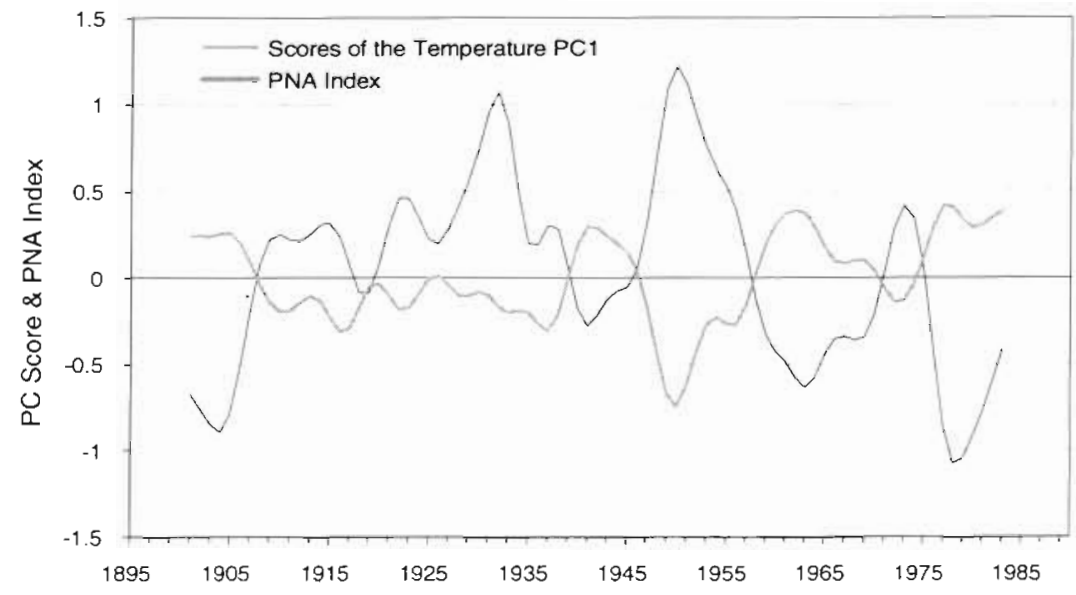

Fig. 9. Scores of the temperature PC1 and the extended PNA index, after passing through the 11 -year low-pass filter 


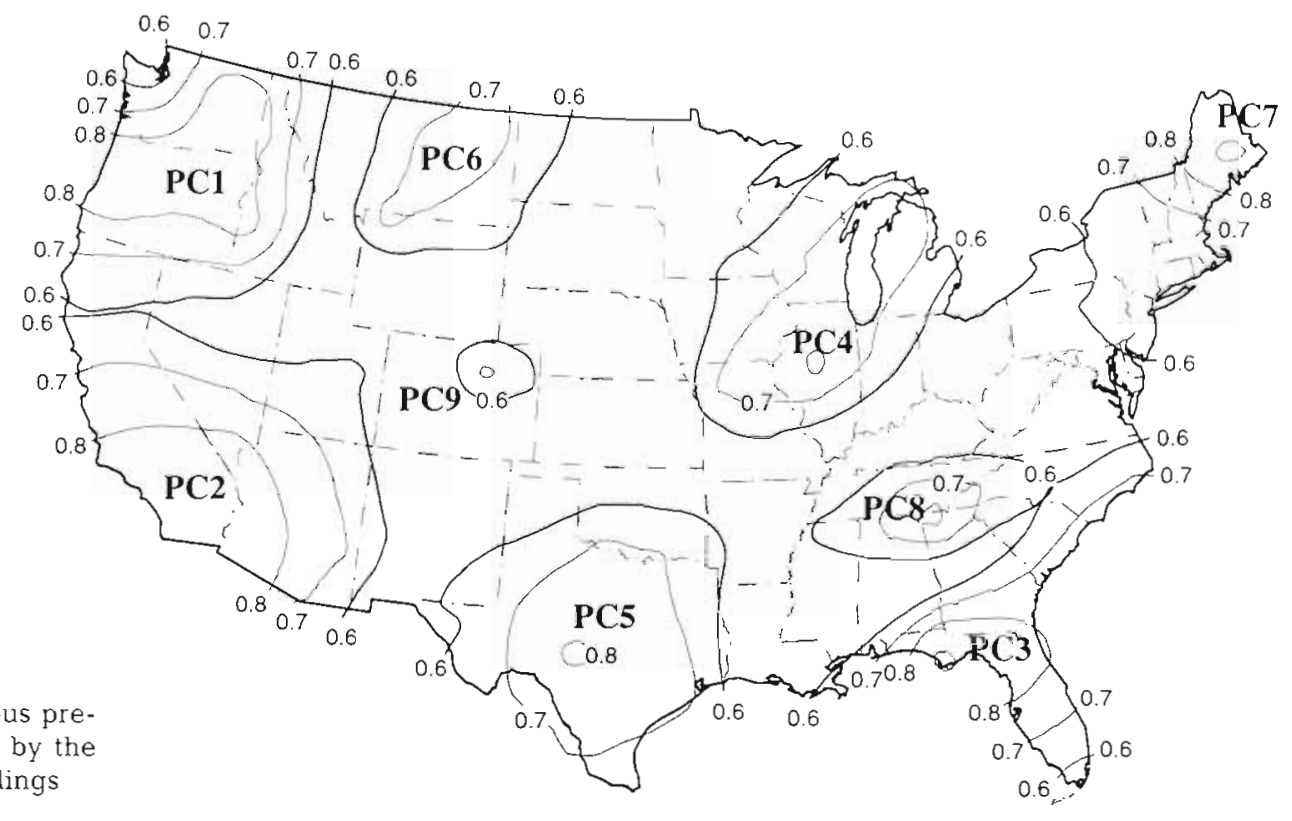

Fig. 10. Regions of homogeneous precipitation regimes represented by the rotated precipitation $\mathrm{PC}$ loadings

original data. Fig. 10 shows the core areas represented by the rotated PCs, namely, areas with the highest loadings of the specific PCs.

Statistically significant correlations were found between the PNAI and 5 out of the 9 rotated precipitation PCs (Table 7). Along the Gulf and south Atlantic coasts, precipitation anomalies are positively correlated with the PNAI. In the northern Great Plains, southwest, midwest, and the southern Appalachians, precipitation anomalies are negatively correlated with the PNAI. To investigate long-term temporal variations, scores of the 5 PCs were passed by the 11 -year low-pass filter, and plotted over time with the filtered PNAI (Fig. 11). In the area represented by PC2 (southwest), wet periods occurred around 1910, late 1930s to early 1940s, late 1960s, and late 1970s. Dry periods occurred around the turn of the century, 1920s, late 1940 s to early 1960 s, and early 1970 s. Although there is a tendency for dry conditions to be associated with

Table 7. Correlation of the rotated precipitation principal components to the winter PNA index

\begin{tabular}{|ccc|}
\hline $\begin{array}{c}\text { Precipitation } \\
\text { principal component }\end{array}$ & $\begin{array}{c}\text { Correlation } \\
\text { coefficient }\end{array}$ & Significance \\
\hline PC1 & -0.065 & 0.5385 \\
PC2 & -0.211 & 0.0425 \\
PC3 & 0.360 & 0.0004 \\
PC4 & -0.388 & 0.0001 \\
PC5 & -0.028 & 0.7873 \\
PC6 & -0.417 & 0.0001 \\
PC7 & 0.008 & 0.9414 \\
PC8 & -0.417 & 0.0001 \\
PC9 & -0.049 & 0.6402 \\
\hline
\end{tabular}

high PNAI values and wet conditions with low PNAI values, the PNA teleconnection pattern cannot explain some of the interdecadal variation patterns. For example, the PNAI values during the 1920 s, late 1940 s, and early 1970 s are mostly negative, while drought conditions occurred in the region. In the area represented by PC3 (southeastern coasts), wet conditions are found around the turn of the century, early 1910s, early 1940s, and the period after 1960, while drought conditions are found around 1910, late 1920s to early 1930 s, and late 1940 s to 1950 s. Most wet periods are associated with positive PNAI values. Perhaps more significantly, almost all drought periods are associated with negative PNAI values. In the regions represented by PC4 (midwest), PC6 (northern Great Plains), and PC8 (southern Appalachians), wet periods are usually associated with negative PNAI values and dry periods with positive PNAI values. Among the 5 regions examined here, the PNAI can only explain the long-term trend in precipitation anomalies along the southeastern coasts (PC3). Nevertheless, the relationships between regional precipitation anomalies and the PNAI confirm that the index can be useful in studies of local climatic conditions in certain parts of the continental United States.

\section{The PNA teleconnection pattern and ENSO events}

The relationship between the PNA teleconnection pattern and ENSO events has attracted great attention (Yarnal 1985). The Southern Oscillation (SO) is the seasurface pressure seesaw between the tropical east and west Pacific. The El Niño (The Boy) and La Niña (The 

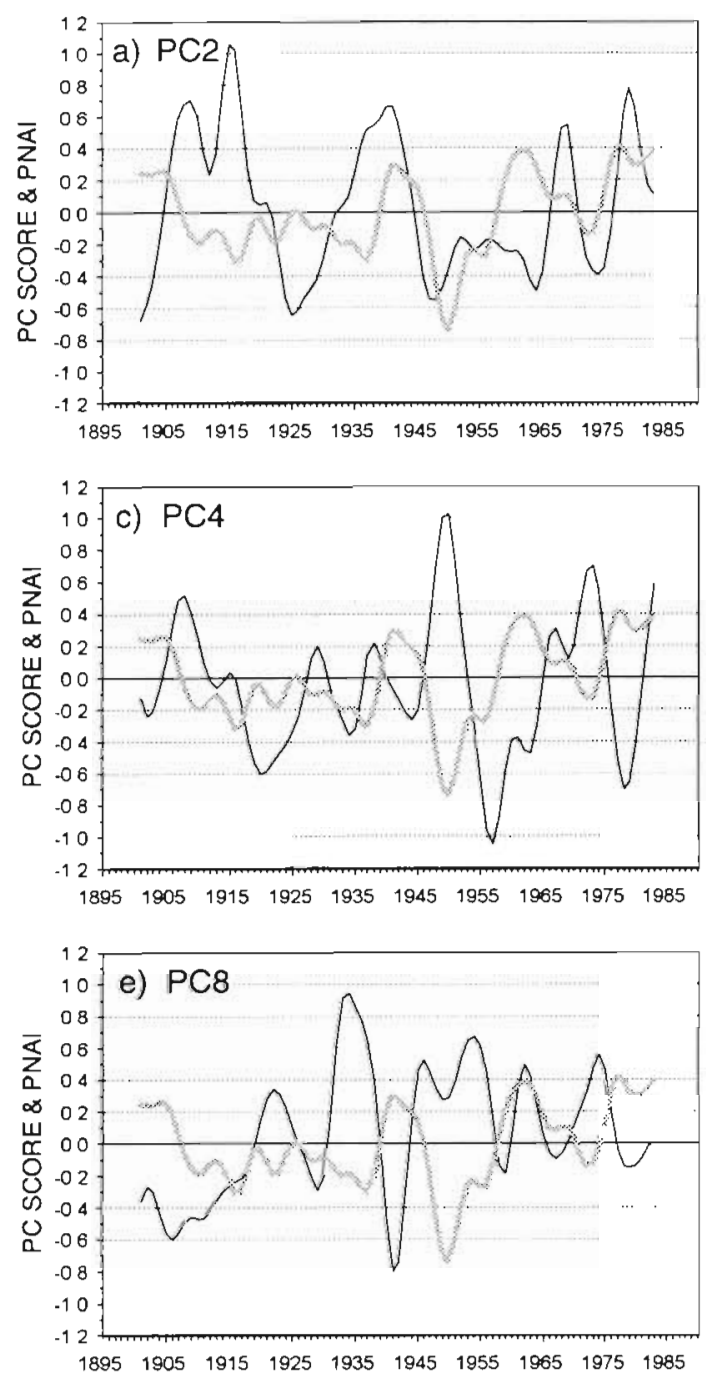

Girl) are the oceanic component of the SO (Philander 1990). Durnng the El Niño (EN) or warm events, exceptıonally warm water in the equatorial east Pacifıc is regarded as the thermal forcing for the elevated ndge in the mid-troposphere in the extratropical area, which is typical during the PNA phase (Yarnal 1985). The opposite phase of the oscillation is the La Nina (LN) or cold events, during which abnormal cooling occurs in the equatorlal east Pacific. They may also have significant extratropical impacts, but are much less well known than the warm events. Horel \& Wallace (1981) examined 7 warm events during the perrod 1951 to 1978. They concluded that the PNA phase tends to occur during warm events. Yarnal \& Diaz (1986) derived similar conclusions when examining the PNA pattern in relation to the tropical thermal forcing However, many previous studies based on observed data are inconclusive as the results could not be venfled using statistical methods. During the period 1947
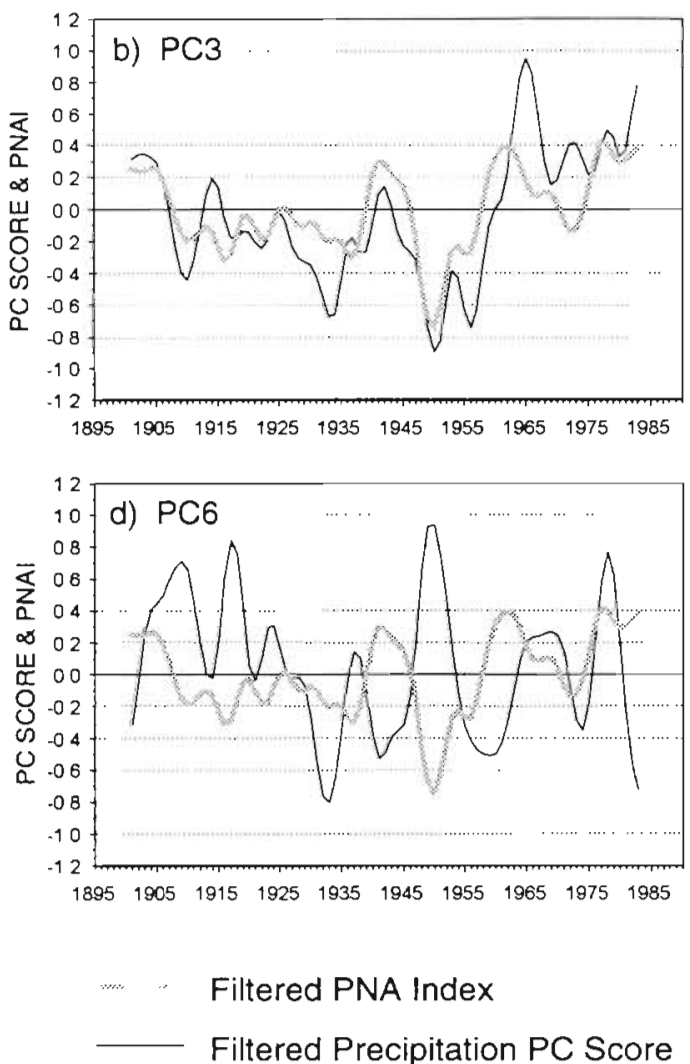

Fig. 11 Scores of the rotated precipitation $P C s$ that are significantly correlated with the PNA index, after passing through the 11 -year low-pass filter

to 1988 in which the measured PNAI data are available, there are less than 10 moderate-strong warm events. So few observations can barely provide meaningful results using conventional statistical methods. To achieve results of statistical significance, monthly values were pooled together to increase the size of data sets. For example, Klein \& Kline (1984) examined the data for 34 winters. Instead of using the seasonal values, they used individual monthly values to derive a data set with 102 observations. Although in this way the sample size is increased, the data also incorporate unwanted autocorrelation associated with monthly data and, therefore, increase difficulties in certain statistical analyses. Hamilton (1988) used surface climatic data, such as precipitation at various locations, to reconstruct extratropical teleconnection patterns since 1899. He found only 9 out of 15 strong warm events displaynng extratropical responses similar to the PNA phase. An earlier study by Hamilton \& Garcia 
(1986) used proxy data to reconstruct the records of the warm events and extratropical teleconnection patterns from 1531 to 1841 . However, they could not establish a direct link between the warm events and the extratropical atmospheric conditions. These contradictions may be because the proxy data could not accurately portray the characteristics of the PNA teleconnection pattern.

In the present study, the relationship between the PNA pattern and the ENSO events was investigated using the PNA and SO indices. There are different ways to calculate the $\mathrm{SO}$ index (SOI), but the most commonly used methods are based on the sea-surface pressure difference between Darwin $\left(12.4^{\circ} \mathrm{S}, 130.9^{\circ} \mathrm{E}\right)$, Australia, and Tahiti $\left(17.5^{\circ} \mathrm{S}, 149.6^{\circ} \mathrm{W}\right)$ in the east Pacific (Wright 1984). For the present study, an extended SOI of the Climate Analysis Center version is adopted (Ropelewski \& Jones 1987). This index is the normalized difference between the pressure anomalies at Darwin and Tahiti (Climate Analysis Center 1986). Large negative values indicate the warm events and large positive values indicate the cold events. This extended version of the SOI goes back to 1882. As EN events are most prominent during the winter months, the focus of the present study is the winters when a strong EN or LN event was in force. There are missing values in the winters of 1893, 1894, 1895, 1907, 1908, 1915, and 1932. Previous studies indicated that 1915 may be a weak-to-moderate warm-event year and 1932 a very weak warm-event year, while the other missing years are neither warm- nor cold-event years (Rasmusson 1984, Wright 1984, Quinn et al. 1987 , Webb \& Betancourt 1992). The winter SOI during the period 1882 to 1988 has a mean of 0.007 and standard deviation of 0.878 .

To identify strong warm and cold events, the 93 winters during the period 1895 to 1988 were classified into 3 groups according to the SOI: a group with values below 1.0 standard deviation from the long-term mean (the warm-event winters), a group with values above 1.0 standard deviation from the mean (the cold-event winters), and a group with values between the -1.0 and +1.0 standard deviations (the transitional winters). The years with missing SOI values were discarded. There are 14 strong warm-event winters and 12 strong cold-event winters during this period (Table 8).

A 1-way ANOVA was performed on the group means of the extended PNAI (Table 9). The results suggest significant differences among the group means. In other words, the strength of the PNA pattern is significantly different between the warm-event, cold-event and transitional winters. A nonparametric test (Kruskal-Wallis $H$-test) gave the same conclusion. A Tukey's studentized-range test (post hoc test) on multiple group-means revealed that the mean of the
Table 8. Strong El Niño and La Niña winters according to the SO index from 1895-96 to 1987-88, with missing values being discarded

\begin{tabular}{|cccc|}
\hline EN winters & SOI & LN winters & SOI \\
\hline 1903 & -0.93 & 1898 & 1.10 \\
1905 & -0.97 & 1904 & 1.33 \\
1906 & -0.97 & 1918 & 1.60 \\
1912 & -1.13 & 1929 & 1.37 \\
1919 & -1.30 & 1939 & 1.23 \\
1926 & -1.07 & 1943 & 1.07 \\
1941 & -1.67 & 1950 & 0.93 \\
1942 & -1.03 & 1951 & 1.40 \\
1958 & -1.03 & 1956 & 1.07 \\
1959 & -1.07 & 1971 & 1.13 \\
1973 & -1.13 & 1974 & 1.80 \\
1978 & -1.47 & 1976 & 1.47 \\
1983 & -3.13 & & \\
1987 & -1.27 & & \\
\hline
\end{tabular}

PNAI in the warm-event winters is significantly different from those during the cold-event and transitional winters. During the warm-event winters, the mean PNAI is 0.474, indicating the occurrence of a fairly strong PNA phase; during the cold-event winters, the mean PNAI is -0.286 , indicating the occurrence of a weak RPNA phase. However, as implied by the Tukey's test, the means of the PNAI in cold-event and transitional winters are not significantly different from each other. Therefore, the hypothesis that the cold events have significant extratropical impact in the form of the RPNA phase cannot be established using the current data. This is also probably why there is a relatively low correlation coefficient $(0.388)$ between the PNA and SO indices, suggesting a rather weak relationship although statistically significant. Such a rela-

Table 9. One-way ANOVA, Kruskal-Wallis $H$-test, and post hoc test on the means of the PNA index during various SO phases

\begin{tabular}{|c|c|c|c|c|}
\hline $\begin{array}{l}\text { ANOVA } \\
\text { SO phase }\end{array}$ & Mean PNAI & $\mathrm{n}$ & $F$-ratio & Significance \\
\hline El Niño & 0.474 & 14 & 7.26 & 0.0012 \\
\hline Transition & 0.008 & 63 & & \\
\hline La Niña & -0.286 & 12 & & \\
\hline \multicolumn{5}{|c|}{ Kruskal-Wallis $H$-test (Chi-square approximation) } \\
\hline Chi-square & 14.066 & & Significance & 0.0009 \\
\hline \multicolumn{5}{|c|}{$\begin{array}{l}\text { Tukey's studentized-range test on group means } \\
\text { Minimum significant difference }=0.420\end{array}$} \\
\hline \multicolumn{5}{|c|}{ Significance of differences between the PNAI means: } \\
\hline & El Niño & & Transition & \\
\hline Transition & Significant & & & \\
\hline La Niña & Significant & & t significant & \\
\hline
\end{tabular}




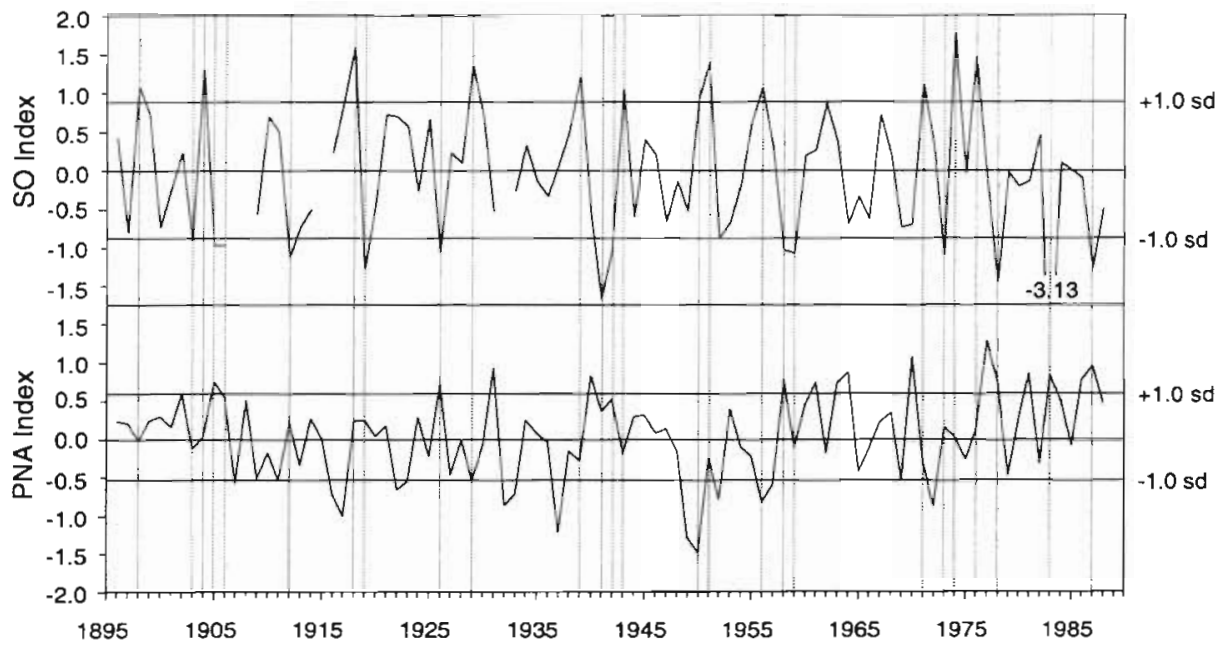

Fig. 12. The PNA and SO indices from 1895 to 1988 . Vertical lines mark strong El Niño and La Niña winters tionship is also illustrated by plotting the PNA and SO indices over time (Fig. 12). When there is a strong warm (or cold) event, there always seems to be some extratropical response in the form of the PNA for RPNA) phase. However, the strength of the PNA teleconnection pattern is rather variable, and many of the PNAI values are well inside the -1.0 and +1.0 standard deviation range. In addition, some strong PNA (1902, 1961, 1963, 1977, 1981, and 1986) and RPNA (1916, 1933, 1937, 1957, and 1972) winters do not coincide with large positive or negative SOI values that indicate cold or warm events. Of course, had the lag-effect and values in other seasons been considered, there might have been more PNA (or RPNA) winters associated with the EN (or LN) events. The results seem to conform with conclusions from previous modeling studies, that the PNA teleconnection pattern may occur with or without the tropical ocean thermal forcing (Blackmon et al. 1983, Shukla \& Wallace 1983, Simmons et al. 1983, Geisler et al. 1985). The tropical thermal forcing may enhance or, under certain circumstances, even cause the PNA pattern, but it is likely not the only cause.

\section{CONCLUSIONS}

In several previous studies, the PNA index based on the $700 \mathrm{mb}$ geopotential height anomaly field has been found to be useful in explaining surface climatic conditions. However, its short record length may seriously limit its application in climatological studies as the measured upper-level data are only available since the late 1940s. Based on the assumption that winter surface temperatures in the continental United States are related to the $700 \mathrm{mb}$ height field, a regression model for the winter PNA index was developed to reconstruct the winter PNA teleconnection pattern during the period 1895 to 1947. Principal components of the temperature anomaly field data across the United States were used as the independent variables. The model explained $89 \%$ of the variance in the PNA index and the residual analysis suggested that the estimates were unbiased. In this way, an accurate portrayal of the characteristics of the winter PNA pattern for the entire period from 1895 to 1988 was derived.

To illustrate potential applications of the extended record of the winter PNA teleconnection pattern, results of correlations of the PNA index to precipitation anomalies across the United States were compared between the 2 different time periods 1947 to 1988 and 1895 to 1988 . The longer record revealed areas of significant correlation which were not displayed by the shorter record. The longer record also provided more extreme cases of the PNA teleconnection pattern. Therefore, the composite maps of the surface conditions for the PNA and RPNA phases based on the extended record should be more representative. The extended PNA index can also be used to explain interannual and long-term variations in temperature and precipitation anomalies in various parts of the United States. It may be especially useful in explaining the cooling trend in the eastern United States from the 1940 s to the 1970s. Finally, the extended PNA index was used to investigate the relationship between the PNA teleconnection pattern and ENSO events. The PNA phase tends to occur during the warm events. However, the association between the 2 most important teleconnection patterns is rather weak. It is especially unclear whether the RPNA phase tends to occur during the cold events. Based on the results from this study, it is conceivable that the extended winter PNA index can be used in other climatological studies where a long record is desirable. 
Acknowledgements. This project was in part supported by a Research Initiation Grant from Georgia State University (GSU\#94-005). The author thanks Dr Julio Betancourt at the Desert Laboratory of the U.S. Geological Survey, Dr Daniel Leathers at the University of Delaware, and Dr Peter Robinson at the University of North Carolina at Chapel Hill for providing some of the data used in this study. Thanks also to Jeffrey McMichael and Melissa Massaro of the Cartographic Laboratory at the Department of Geography, Georgia State University, for their help in producing maps in this article.

\section{LITERATURE CITED}

Agee, E. M. (1980). Present climatic cooling and a proposed causative mechanism. Bull. Am. Meteorol. Soc. 61 $1356-1367$

Barnston, A. G., Livezey, R. E. (1987). Classification, seasonality and persistence of low-frequency atmospheric circulation patterns. Mon. Weather Rev. 115: 1083-1126

Blackmon, M. L., Geisler, J. E., Pitcher, E. J. (1983). A general circulation model study of January climate anomaly patterns associated with interannual variations of equatorial Pacific sea surface temperatures. J. Atmos. Sci. 40: 1410-1425

Blackmon, M. L., Lee, Y. H., Wallace, J. M. (1984a). Horizontal structure of $500 \mathrm{mb}$ height fluctuations with long, intermediate and short time scales. J. Atmos. Sci. 41. 961-979

Blackmon, M. L., Lee, Y. H., Wallace, J. M., Hsu, H. H. (1984b). Time variation of 500 height fluctuations with long, intermediate and short scales as deduced from lagcorrelation statistics. J. Atmos. Sci. 41: 981-991

Climate Analysis Center (1986). Climate diagnostics bulletin, global analyses and indices. No. 86/4. NOAA/National Weather Service/National Meteorological Center, Washington, DC

Englehart, P. J., Douglas, A. V. (1985). A statistical analysis of precipitation frequency in the conterminous United States, including comparisons with precipitation totals. J. Clim. appl. Meteorol. 24: 350-361

Erickson, C. O. (1984). Hemispheric anomalies of $700 \mathrm{mb}$ height related to mean temperature for fall, winter and spring in the United States. Mon. Weather Rev, 112: $465-473$

Esbensen, S. K (1984). A comparison of intermonthly and interannual teleconnections in the $700 \mathrm{mb}$ geopotential height field during the Northern Hemisphere winter. Mon. Weather Rev. 112: 2016-2032

Geisler, J. E., Blackmon, M. L., Bates, G. T., Munoz, S. (1985). Sensitivity of January climate response to the surface temperature anomalies. J. A.tmos. Sci. 42: 1037-1049

Glantz, M. H. (1990). Introduction. In: Glantz, M. H., Katz, R. W., Nicholls, N. (eds.) Teleconnections linking worldwide climate anomalies: scientific basis and societal impact. Cambridge University Press, Cambridge, p. 1-12

Hamilton, K. (1988). A detailed examination of the extratropical response to tropical El Niño/Southern Oscillation events. J. Climatol. 8: 67-86

Hamilton, K., Garcia, R. R. (1986). El Niño/Southern Oscillation events and their associated midlatitude teleconnections 1531-1841 Bull. Am. Meteorol. Soc. 67: 1354-1361

Horel, J. D., Wallace, J. M. (1981). Planetary-scale atmospheric phenomena associated with the Southern Oscillation. Mon. Weather Rev. 109: 813-829

Johnston, J. R. (1978). Multivariate statistical analysis in geography. Longman, New York

Karl, T. R., Koscielny, A. J. (1982). Drought in the United States: 1895-1981. J. Climatol. 2: 313-329
Klein, W. H., Bloom, H. J. (1987). Specification of monthly precipitation over the United States from the surrounding $700 \mathrm{mb}$ height field. Mon. Weather Rev. 115: 2118-2132

Klein, W. H., Kline, J. M. (1984). The synoptic climatology of monthly mean surface temperature in the United States during winter relative to the surrounding $700 \mathrm{mb}$ height field. Mon. Weather Rev. 112: 433-448

Lambert, S. J. (1990). Discontinuities in the long-term Northern Hemisphere 500-mb heights dataset. J. Clim. 3: 1479-1484

Leathers, D. J., Palecki, M. A. (1992). The Pacific/North American teleconnection pattern the United States climate. Part Il: Temporal characteristics and index specification. J. Clim. 5: 707-716

Leathers, D. J., Yarnal, B., Palecki, M. A. (1991). The Pacific/ North American teleconnection pattern the United States climate. Part I: Regional temperature and precipitation associations. J. Clim. 4: 517-528

Mitchell, J. M. Jr, Dzerdzeevskii, B., Flohn, H., Hofmeyr, W. L., Lamb, H. H., Rao, K. N., Wallén, C. C. (1966). Climatic change. Technical Note 79, World Meteorological Organization, Geneva

Philander, S. G. (1990). El Niño, La Niña, and the Southern Oscillation. Academic Press, New York

Quinn, W. H., Neal, V. T., Antunez de Mayolo, S. E. (1987). El Niño occurrence over the past four and a half centuries. J. geophys. Res. 92(C): 14449-14461

Rasmusson, E. M. (1984). El Niño, the ocean/atmosphere connection. Oceanus 27: 5-12

Richman, M. B. (1986). Rotation of principal components. J. Climatol. 6: 293-335

Robinson, P. J., Walsh, S. J. (1991). Precipitation regime changes associated with climatic changes. Water Resources Research Institute of the University of North Carolina, Raleigh

Rogers, J. C. (1984). The association between the North Atlantic Oscillation and the Southern Oscillation in the Northern Hemisphere. Mon. Weather Rev. 112: 1999-2015

Ropelewski, C. F., Jones, P. D. (1987). An extension of the Tahiti-Darwin Southern Oscillation Index. Mon. Weather Rev. 115: 2161-2165

Shukla, J., Wallace, J. M. (1983). Numerical simulation of the atmospheric response to equatorial Pacific sea surface temperature anomalies. J. Atmos. Sci. 40: 1613-1630

Simmons, A. J., Wallace, J. M., Branstator, G. W. (1983). Barotropic wave propagation and instability, and atmospheric teleconnection patterns. J Atmos. Sci. 40: $1363-1392$

Skeeter, B. R. (1990). Variations in the association between mid-tropospheric flow and surface temperatures across the United States. Ann. Ass. Am. Geogr. 80: 590-602

van Loon, H., Williams, J. (1977). The connection between trends of mean temperature and circulation at the surface. Part IV Comparison of the surface changes in the Northern Hemisphere with the upper air and with the Antarctic in winter. Mon. Weather Rev. 105: 636-647

Wallace, J. M., Gutzler, D. S. (1981). Teleconnections in the $500 \mathrm{mb}$ geopotential height field during the Northern Hemisphere winter. Mon. Weather Rev. 109: 784-812

Webb, R. H., Betancourt, J. L. (1992). Climatic variability and flood frequency of the Santa Cruz River, Pima County, Arizona. U.S. Geological Survey Water Supply Paper 2379, Government Printing Office, Washington, DC

White, D., Richman, M., Yarnal, B. (1991). Climate regionalization and rotation of principal components. J. Climatol. 11. $1-25$

Wright, P. B. (1984). Relationships between indices of the Southern Oscillation. Mon. Weather Rev. 112: 1913-1919 
Yarnal, B. (1985). Extratropical teleconnections with El Niño/ Southern Oscillation (ENSO) events. Prog. phys. Geogr. 9: 315-352

Yarnal, B., Diaz, H. F. (1986). Relationships between extremes of the Southern Oscillation and the winter climate of the Anglo-American Pacific coast. J. Climatol. 6: 197-219

Yarnal, B., Leathers, D. (1988). Relationships between interdecadal and interannual climatic variations and their effect

Editor: V. Meentemeyer, Athens, Georgia, USA on Pennsylvania climate. Ann. Ass. Am. Geogr. 78: 624-641 Yin, Z. (1994). Moisture regime in the southeastern United States and teleconnection patterns. Int. J. Climatol. (in press)

Zishka, K. M., Smith, P. J. (1980). The climatology of cyclones and anticyclones over North America and surrounding ocean environs for January and July 1950-1977. Mon. Weather Rev. 108: 387-401

Manuscript first received: February 21, 1994

Revised version accepted: June 9, 1994 